\title{
TAX CREDITS, INCOME SUPPORT AND PARTNERSHIP DECISIONS
}

\author{
DAN ANDERBERG
}

\section{CESIFO WORKING PAPER NO. 2147 \\ CATEgORY 1: PUblic FinANCE \\ NOVEMBER 2007}

Presented at CESifo Area Conference on Employment and Social Protection, May 2007

\author{
An electronic version of the paper may be downloaded \\ - from the SSRN website: WWw.SSRN.com \\ - from the RePEc website: $\quad$ www.RePEc.org \\ - from the CESifo website: www.CESifo-group.org/wp
}




\title{
TAX CREDITS, INCOME SUPPORT AND PARTNERSHIP DECISIONS
}

\begin{abstract}
This paper considers the potential impact of welfare benefits on the partnership status of women in the UK. Using recent policy reforms to identify the response rate I find that a $£ 100 /$ week welfare benefit "partnership penalty" reduces the probability of a woman having a partner by seven percentage points. I also use the model to explore the potential effects of the recent Tax Credit reforms on partnership rates; I find that while the 1999 WFTC reform improved partnership incentives this effect was effectively undone by the 2003 WTC/CTC reform.
\end{abstract}

JEL Code: H31, I38, J12.

Keywords: welfare benefits, tax credits, family structure.

Dan Anderberg

Department of Economics

Royal Holloway University of London

Egham, Surrey, TW20 OEX

United Kingdom

Dan.Anderberg@rhul.ac.uk

November 13, 2007 


\section{Introduction}

The fraction of household headed by single women with dependent children has increased rapidly in many countries in the recent decades. The UK is no exception in this case. At the same time, the employment rate of lone mothers fell substantially relative to that of married mothers between the late 1970s and the mid 1990s (Gregg and Harkness, 2003). The combination of these trends contributed to a steady rise in the poverty rate among children.

As a result of such concerns, several countries have initiated or expanded a range of policies aimed at supporting working families on low income. An important forerunner in this context was the US Earned Income Tax Credit (EITC). Up until the mid-1980s the EITC had been a relatively small programme. However, through a sequence of expansions the EITC has emerged as one of the main welfare programmes offering support to low-income families (Hotz and Scholz, 2003). The EITC is fundamentally different from more traditional welfare programmes in that it only offers benefits to households with at least one working adult. The design of the EITC is such that it is considered by many as promoting both "family and work". As such it can be viewed as a key part of a wider strategy to combat poverty by encouraging labour supply as well as the formation of two-parent households.

The UK has long had a policy of in-work benefits but like the EITC the UK family tax credits were for a long time overshadowed by more traditional welfare programmes like Income Support (IS). In October 1999 the existing Family Credit (FC) programme was, however, replaced by the considerably more generous Working Families' Tax Credits (WFTC). ${ }^{1}$ The WFTC became one the Labour government's flagship policies for combating poverty among children. Indeed, the WFTC was subsequently reformed again in April 2003 and relaunched under the name Working Tax Credit (WTC); at the same time the child premia that had been available under IS and WFTC were collected under a single programme known as Child Tax Credit (CTC). While being logically separate programs, the WTC and CTC are nevertheless interrelated e.g. by being subject to a single means-test. A novel feature of the WTC programme was that it expanded the set of potential recipients to also include, for the first time, childless individuals and couples. While there has been a number of studies of the labour supply effects of the WFTC reform in particular, little is known about the tax credits' impact on family structure. ${ }^{2}$

\footnotetext{
${ }^{1}$ See Blundell (2002) for a survey and discussion of both the WFTC and other "Welfare-to-Work" policies.

${ }^{2}$ Contributions that evaluate and discuss the labour supply effects of the WFTC reform include Blundell et al. (2000), Brewer et al. (2007), Blundell and Hoynes (2004), Gregg and Harkness (2003), Francesconi and van
} 
Indeed, the potential impact of welfare programmes on family structure is a highly contentious issue. A substantial US literature examines whether more generous welfare programs are associated with higher rates of female household headship. Much of this literature has exploited variation across US states to identify the effect of welfare. While the early literature found statistically significant effects the more recent literature has highlighted the fragility of these results. Moffitt (1994) showed that the estimates of the effect of welfare benefits on female headship are highly sensitive to the inclusion of state-fixed effects. Hoynes (1997) took one further step by adding individual-fixed effects; she shows that welfare benefits are positively correlated with both individual and state effects, casting serious doubt on the results from the early literature: when both individual and state effects are included there is no longer any statistically significant effect of welfare. ${ }^{3}$ A few recent studies have looked more particularly at the potential effect of the EITC. Eissa and Hoynes (2003) exploit a number of policy changes, including the EITC expansion, to identify the effect of taxes and transfers on marital status. ${ }^{4}$ They find that taxes and transfers do affect marriage behavior, but that the responses are quite modest (see below). ${ }^{5}$

In contrast there is very little work available on the effect of welfare benefits on partnership status in the UK context. Two recent exceptions are Francesconi and van der Klaauw (2007) and Walker and Zhu (2006). The first paper looks at the effect of the 1999 WFTC reform on a variety of outcomes, including the rate of entry into partnerships. The authors use an extended difference-in-difference approach; identification of the effect of the reform is achieved by the fact that WFTC eligibility requires the presence of at least one child in the household. By effectively contrasting the rate of entry into partnership for single mothers to that of single women without children they conclude that the WFTC reform has had a small but significant negative effect on der Klaauw (2007).

${ }^{3}$ Moffitt (1992) surveys the literature up to the early 1990s. Subsequent surveys are provided by Moffitt (1998). See also Hoynes (1997). Rosenzweig (1999) argues that models that identify the effect of policy through year-to-year variation are likely to underestimate the policy effects; he suggest using a cohort-based approach, where a woman's partnership status in early adulthood is linked to the average benefits to which she was exposed during her teenage years. Using this approach, Rosenzweig finds larger policy responses than e.g. Moffitt (1994) and Hoynes (1997).

${ }^{4}$ See also Dickert-Conlin and Houser (1999) and Ellwood (2000).

${ }^{5}$ There is also an emerging literature that looks at the effect of the 1996 US welfare reform on family structure. See e.g. Schoeni and Blank (2000) and Bitler et al. (2004). Moreover, there is an emerging literature that considers the impact of the EITC on fertility (Baughman and Dickert-Conlin, 2003). 
the rate of entry into partnerships for single mothers. The second paper finds that child support liabilities and entitlements have a sizeable impact on separation probabilities. The authors also point out that expected child support net payments do not always equal expected receipt due to the benefit system. Hence Walker and Zhu identify an indirect channel through which the benefit system affects partnership dissolution.

The empirical strategy followed in the current paper is very different from these last two papers and follows more closely Eissa and Hoynes (2003). I examine the effect of the family Tax Credits (by which I mean FC, WFTC, and WTC/CTC) and the IS programme on the propensity to have a partner. I estimate a simple model where the probability of having a partner depends on individual characteristics, region of residence, year and, importantly, the benefit consequences of having a partner. The benefit consequences of having a partner are modelled for each individual. I use data that covers the years 1995 to 2004 and the effect of policy is identified due to the fact that both the tax credits and IS were reformed during this time period.

While the basic empirical strategy is the same as in Eissa and Hoynes (2003), there are also key differences both in focus and implementation. In contrast to Eissa and Hoynes who focus on marriage as outcome I consider whether or not a woman has a partner (either married or cohabiting). ${ }^{6}$ Also, I focus exclusively on welfare benefits, not income taxes. This is simply because the UK tax system is individually-based and hence generates negligible incentive for or against partnership formation. A key difference in implementation is that I allow female labour supplies to be partnership-state-dependent. That is, I allow for the possibility that some women would change their labour force participation status if their partnership status were to change. Another difference in implementation is that I allow for non-linearities in the assignment of partner characteristics (and labour supplies) to the women in the data by adopting a flexible matching approach.

The rest of the paper is outlined as follows. Section II outlines the two benefit programmes considered - the tax credits and IS - and provides examples of how these programmes can provide financial incentives either for or against partnership formation. Section III discusses the data used and provides a brief descriptive analysis of the distribution of partnership bonuses and penalties facing the women in the data. Section IV outlines the empirical framework and how it is implemented while Section V presents the regression results. Section VI then takes a

\footnotetext{
${ }^{6}$ Eissa and Hoynes (2000) focus on the choice between cohabitation and marriage.
} 
closer look at the likely impact of the WFTC and the WTC/CTC reforms on partnership rates using the results obtained. Finally, Section VII concludes.

\section{The Benefit System and Stylized Examples}

The current analysis will focus on two main benefit programmes: the (family) tax credits (FC, WFTC and WTC/CTC) and Income Support (IS). Both programmes are aimed at low-income households. The two programmes also connect naturally: while the tax credits are an "in-work benefit" programme in that eligibility requires that some adult in the household works at least 16 hours per week, IS is only available to individuals who work less than 16 hours. This section briefly describes the two benefit programmes and how they can generate partnership bonuses and penalties. ${ }^{7}$

\section{The Tax Credits}

The current analysis will span three generations of the UK family tax credit programme: FC which was in operation between 1988 and 1999, WFTC which replaced FC in October 1999, and WTC/CTC which replaced WFTC (and parts of IS) in 2003-2004.

The WFTC and FC shared the same structure, providing in-work support to low-paid working adults and couples with dependent children. A household would be eligible for tax credits provided that some adult worked 16 or more hours per week and there was at least one dependent child. A household's maximum weekly credit was made up of a basic adult element, credits for each child, childcare credits (if applicable) and a bonus for working for 30 hours or more per week. The 1999 WFTC reform was largely a set of changes in the programme's parameter values, increasing its generosity. First, the income threshold above which the benefit was tapered away grew. Second, the benefit withdrawal (or "taper") rate was reduced. Third, the credits for younger children grew; this last change effectively eliminated the variation in

\footnotetext{
${ }^{7}$ Benefits not considered in the analysis include Housing Benefit (HB) and the Council Tax Benefit (CTB). HB is available to people with low incomes who are liable to pay rent on their property. The maximum level of HB is the 'eligible rent'. Similarly, CTB is available to people with low incomes who are liable to pay council tax. HB and CTB are closely tied to IS in that people on IS (or income-based Jobseeker's Allowance) are automatically entitled to the full levels of $\mathrm{HB}$ and CTB. We choose not to model HB and CTB since it would require making detailed assumptions about the accommodation choices in the counterfactual partnership state.
} 
credits by age that existed under the FC programme. ${ }^{8,9}$

In 2003 the WTC and the CTC were introduced. For families with children, the WTC would broadly replicate the in-work support for adults provided through the WFTC programme. However, a novel feature of WTC was that Tax Credits would now also be available to low income working individuals and couples without children (aged 25 or above, working at least 30 hours/week). The WTC is made up of a basic element, a couple's/lone parent element, an additional 30 hour element and a childcare cost element (if applicable). The new CTC programme, on the other hand, separated out the child premia previously provided under WFTC and merged them with the child premia provided under the IS programme (see below). The idea was that the CTC would create a single, seamless system of support for families with children, payable irrespective of the household's work status. The CTC consists of a basic family element, premia for children (and an extra baby-element). After the WTC/CTC reform all child related premia would be obtained through the CTC and not through WTC and IS. However, during a transition period lasting one year, IS recipients continued to receive the child premia through IS rather than through CTC.

There is a threshold income below which the credit is payable in full; at incomes above the threshold the benefit is tapered off at a fixed rate. Indeed, WTC and the CTC, while logically separate programmes, are nevertheless interrelated in that the two programmes are subject to a joint means-test. In the following I will hence treat WTC and CTC as a single programme.

\section{Income Support}

Income support (IS) is a benefit provided to people on low incomes. IS is mainly claimed by lone parents, people who are incapable of work, and carers. ${ }^{10}$ Recipients of IS cannot be working more than 16 hours per week. The calculation of IS entitlement is based on the notion

\footnotetext{
${ }^{8}$ Two further changes that came with the reform implies increased generosity. Any child maintenance received became fully disregarded (while only a small amount was disregarded under FC). Also, the generosity with respect to eligible childcare costs increased.

${ }^{9}$ In April 2001 a small program called the Children's Tax Credit was introduced; this program provided extra income tax relief worth up to $£ 10$ /week to families with children. It was a forerunner to the "family element" in the CTC system introduced in 2003. For completeness, the Children's Tax Credit is included here in the WFTC for the years 2001 and 2002 .

${ }^{10}$ Households with an unemployed adult can claim Job-Seekers Allowance which can be either "contributionbased" or "income-based". The income-based JSA is very similar to IS.
} 
of a personal allowance which depends on age and household composition. To be eligible the claimant's income must be less than their basic personal allowance (plus any premiums and some housing costs). The level of IS payable is the amount needed to top up their income to the relevant amount.

Two major changes in the IS programme obtained during the period that is being studied here. First, between 1998 and 2001 there were a sequence of increases in the premia for children; these implied that the variation in premia by age that used to exist in the IS programme (just like in FC) was gradually removed. Second, when the CTC was introduced, the child premia were, as noted above, taken out of IS and were instead consolidated with the child premia provided through the Tax Credits. However, this migration of IS recipients over to the CTC was only completed in 2004.

\section{Examples of Partnership Bonuses and Penalties}

In the subsequent analysis a couple is said to face a welfare benefit "partnership bonus" (alt. "penalty") if they are entitled to more benefits as a couple than as singles. (See Section III for a formal definition.) In order to illustrate how partnership bonuses and penalties come about it is useful to construct some hypothetical families.

Consider first the Tax Credits. Whether a couple will face a Tax Credit partnership bonus or penalty will depend crucially on individual labour supplies and on family income. I construct four families that differ in terms of the woman's labour force participation and in the wage.

Family 1: "Low wage family with an inactive female". Consider a family, with two children aged 5-10, where the male works full time (40 hours/week) at the $£ 3.60 / \mathrm{hr}$ (the national minimum wage at the beginning of 2000) and where the woman is inactive. The family pays $£ 25$ per week and child for childcare. ${ }^{11}$

Family 2: "Low wage family with an active female". Same as family 1 only the woman also works full time at the minimum wage.

Family 3: "High wage family with an inactive female". Same as family 1 except that the male earns twice the minimum wage per hours, i.e. $£ 7.20 /$ hour.

\footnotetext{
${ }^{11}$ We also assume that the couple has no savings, no mortgage interest payments, and that there are no maintenance payments after separation.
} 
Family 4: "High wage family with an active female". Same as family 3 only the woman also works full time at twice the minimum wage.

Figure 1 illustrates the Tax Credit partnership bonus (penalty if negative) of each family under each year's (April) policy from 1995 to 2004. The top left panel illustrates family 1 and family 2 while bottom panel illustrates family 3 and family 4 .

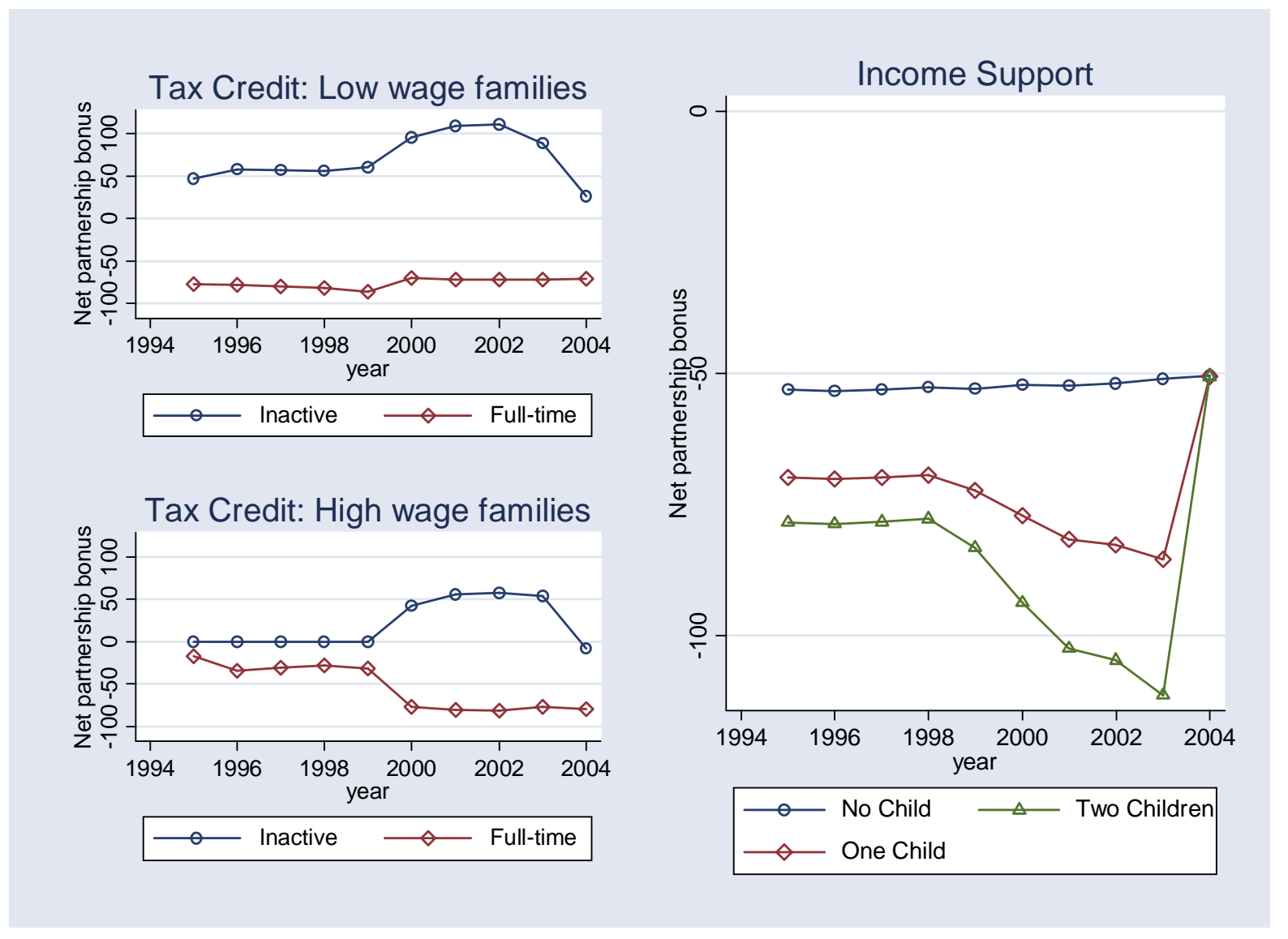

Figure 1: Tax credit and IS net partnership bonuses for some stylized families (in 2000 prices). See text for details.

Family 1 will be the family that faces the largest partnership bonus. Under FC and WFTC, neither the male nor the female would qualify for Tax Credits when living separately; however, as a couple they would. Moreover, the WFTC reform significantly increased the benefits they would qualify for. Under WTC/CTC this family would still obtain a Tax Credit partnership bonus. Note however that he could qualify for WTC as single and she would (in 2004) obtain CTC (but not WTC) as single. The partnership bonus would therefore now only consist of the WTC couple's/family element. Family 2, in contrast, would face a partnership penalty since 
the woman would qualify for Tax Credits as single parent. As a couple they do not, due to the means-test, get the full credit. After the WFTC reform, both the amount that the woman would be entitled to on her own and the amount that they are entitled to as a couple increases by roughly the same amount, leaving the partnership penalty more or less unaffected. Similarly, the WTC/CTC reform had little impact on the implied partnership penalty.

Family 3 is similar to family 1, only that under FC the male's income was too high for the couple to qualify for any Tax Credits. With the more generous WFTC policy they would qualify for some Tax Credits as couple and hence face a partnership bonus. This Tax Credit partnership bonus disappeared, however, with the WTC/CTC reform. Family 4 is similar to family 2 except, as a couple their joint income is high enough that they would not qualify for any Tax Credits under any of the three versions of the programme. The female on her own would qualify for some Tax Credits leading to a partnership penalty; moreover, the penalty increased following the WFTC reform and was maintained by the WTC/CTC reform.

For the purposes of the empirical analysis what is interesting to note is how the WFTC and WTC/CTC reforms will facilitate identification. In particular, Figure 1 highlights how the effects of the reforms, especially the WFTC reform, on the net partnership bonus vary substantially across family types, indeed in some cases in directly opposite directions. The fact that the 1999 reform affected the partnership incentives in opposite directions for different subgroups of the population implies that a standard difference-in-difference approach aiming to uncover the average treatment effect on women with children using as only information the timing of the reform may have low power; in short, there may be substantial responses that "average out". The current paper therefore adopts a more detailed empirical strategy where the policy-generated partnership incentives are explicitly modeled at the individual level. This allows the model to identify the effect of policy using information about how the reform(s) affected the partnership incentives in different subgroups of the population and linking that to the evolution of the group-specific partnership rates.

Consider next IS. Focusing on couples where the male works full time, IS will only generate partnership penalties. Indeed, it will do so for couples where the female is not working and hence will, when living alone, generally qualify for IS. Moreover, since the IS penalty is simply the IS that the female can obtain on her own, neither the male's income nor the female's wage matter for the size of the penalty. The size of the penalty does on the other hand depend crucially on the number and ages of children. The right hand side of Figure 1 shows the IS 
partnership penalty for an inactive woman (above 25 years of age) who has zero, one or two children under the age of 11 . The partnership penalty has been stable for the childless woman, but increased substantially for mothers during the years following 1999. This increase obtained from the gradual increase in the generosity of the IS child premia. When the CTC was fully implemented the child premia were removed from IS implying that the IS partnership penalty no longer varied with the number of children.

Another thing to note is that the Tax Credits- and the IS-partnership net bonuses tend to be strongly negatively correlated. Consider again the four families used above. The two families that face Tax Credit bonuses, i.e. family 1 and 3, will also face (even larger) IS partnership penalties. Conversely, the two families that face Tax Credit partnership penalties, i.e. family 2 and 4, face no IS penalties since the female is also working.

\section{Descriptive Analysis}

\section{Data and Summary Statistics}

I use data from the Family Resources Survey (FRS) 1995-2004. The FRS has the advantage of large samples and the years used contain three important changes in the welfare system: (i) the replacement of FC with WFTC, (ii) the expansion of the IS child premia after 1999, and (ii) the replacement of WFTC (and parts of IS) with WTC/CTC.

The focus of the analysis is on the partnership status of the women in the sample. The sample includes all individuals between the ages of 20 and 55. Pooling across year and excluding retired, long-term sick/disabled, students, self-employed and individuals with incomplete information leaves 117,015 women, 81,554 of whom have partners, and 35,461 who are single.

Table 1 provides summary statistics for the sample of partnered and single women respectively. It shows that the women with partners left school at, on average, the same time as the women without partners. The women with partners are on average nearly four years older than the women without partners. The women with partners also have more children (in all age groups). Partnered and single women have about the same labour force participation rate. ${ }^{12}$ Single women earn slightly more and more often live in a metropolitan area. The earnings of the predicted partners (see below) are slightly higher for the women with partners than for the

\footnotetext{
${ }^{12}$ Single mothers work less frequently than mothers with partners; single non-parents on the other hand work more frequently than partnered non-parents.
} 
single women.

At times it will be convenient to consider women with different levels of education; hence label as "low educated" those women who left full-time education at age 16 or younger, as "medium educated" those women who left full-time education at age 17-19, and as "high educated" those women who left full-time education at age 20 or later.

\section{The Empirical Distribution of Net Partnership Bonuses}

The (net) benefit partnership bonus is defined as the difference between the value of the benefit to which a couple are entitled to when they live together and the sum of the benefits they are entitled to when living apart. Formally consider a couple $i$. Let $B_{i}^{c}$ be the benefit to which the couple are entitled when together and let $B_{i}^{f}$ and $B_{i}^{m}$ be the benefit that the woman and the man are entitled to, respectively, when living separately. The net "partnership bonus" for couple $i$ is then defined as

$$
\Delta B_{i} \equiv B_{i}^{c}-\left(B_{i}^{f}+B_{i}^{m}\right)
$$

(A negative $\Delta B_{i}$ will be referred to as a "partnership penalty".)

In this section I provide some initial descriptive statistics on the distribution of benefit partnership bonuses and penalties for the existing couples in the FRS data. In order to compute partnership bonuses/penalties facing each existing couple I need to calculate not only the benefits that the couple are actually entitled to, but also the benefits they would be entitled to if they were to separate. In simulating these the benefit consequences of the separations I assume that all children reside with the women, that existing savings are divided equally between the partners and that there are no maintenance payments. I also have to make assumptions about what happens to labour supplies and earnings. For the purpose of this descriptive analysis I assume that labour supplies and earnings are unaffected by separation. That is, I compute $B_{i}^{f}$ and $B_{i}^{m}$ at the observed labour supplies and earnings.

The results are illustrated in Figure 2. The top half shows the results for the Tax Credits. The left hand panel shows the fraction of couples facing partnership bonuses/penalties respectively while the right hand panel shows the average bonus (alt. penalty) among those subsidized (alt. penalized) as well as the overall average net bonus. The figure shows that partnership penalties are more frequent than bonuses; the fraction of couples penalized also increased substantially with the WTC/CTC reform. While the 1999 WFTC reform had at most a small impact on the fraction of couples subsidized and penalized, it had a larger effect on the average 
values. In particular, the right hand panel shows that the 1999 reform substantially increased the average partnership bonus among subsidized couples. Looking at the overall net tax credit partnership bonus, we see that the 1999 reform generated an increase of little less than $£ 5$ /week. The WTC/CTC reform went in the opposite direction, partly as a consequence of making tax credits available to single individuals and partly due to the reallocation of the IS child premia into the new CTC programme.
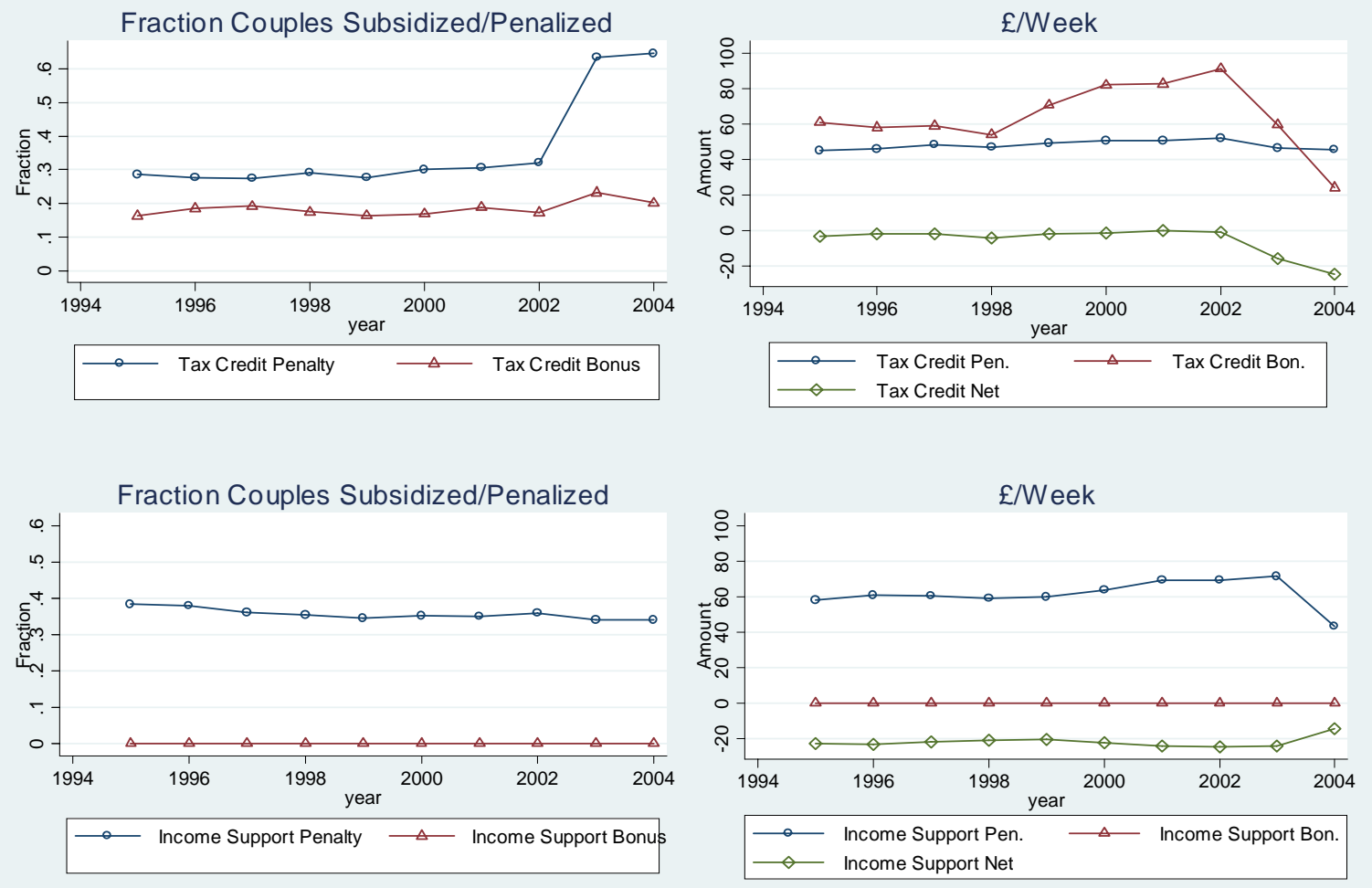

Figure 2: The distribution of Tax Credit and IS partnership bonuses and penalties among existing FRS couples (2000 prices).

The fraction of couples facing IS partnership penalties is somewhere between $35-45$ percent and has been decreasing over time (due to increasing female labour force participation). The average penalty (among the penalized couples) increased from around £55 per week at the beginning of the period to about $£ 70$ per week in 2002 ; this reflects the gradual increase in the child premia from 1999 onwards. A major change came when the IS child premia were moved over to the CTC programme; this reduced IS partnership penalty sharply. This change mirrors the corresponding change in the Tax Credit system. 


\section{Partnership Trends}

Figure 3 shows partnership rates broken down by age group and by educational group. The figure show how the timing of partnership formation differ across educational groups. In the early 20s, the low-educated are generally the most likely to have partners while the higheducated are the least likely to have partners. In the age group 26-35, the partnership rates of the medium- and high-educated have overtaken that of the low-educated. By the late 30s and early 40s the high-educated the most likely to have partners. The figure also indicates a gradual decline in partnership rates. ${ }^{13}$

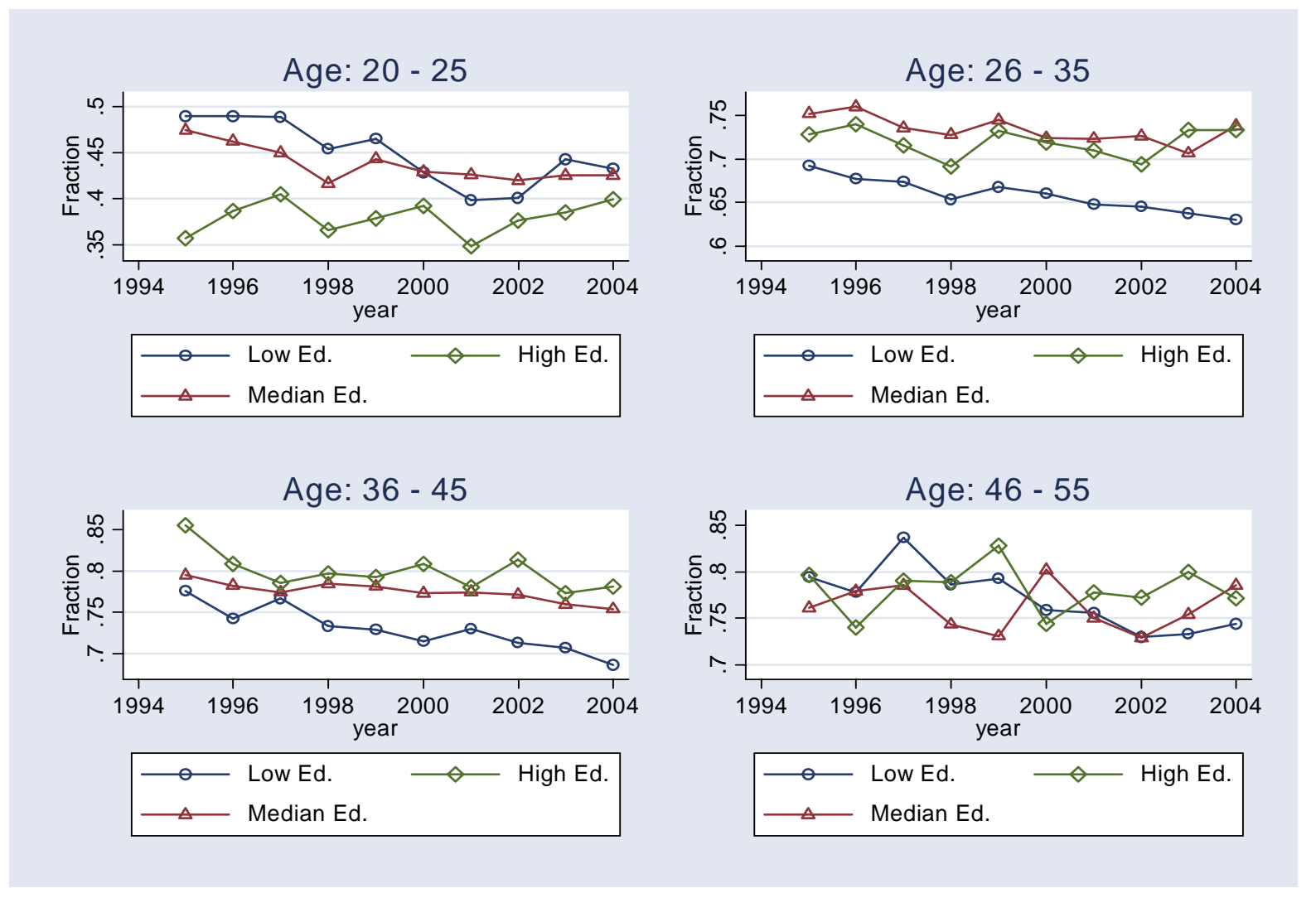

Figure 3: Partnership rates for women in the FRS 1995-2002 by age group.

It is difficult to judge from the figures whether there is any support for the idea that individuals' partnership decisions respond to benefit incentives. Nevertheless, it is interesting to

${ }^{13}$ An potential issue is the degree of accuracy of the measurement of partnership status: Brewer and Shaw (2006) highlight this by noting that the government seems to be paying out tax credits to more lone parents than official statistics suggest live in the UK. Partnership status here is based on self-reported marital/cohabitation status. 
consider what happens around the 1999 WFTC reform which, as noted above, seems to have been generally favourable to partnership formation. Figure 3 suggests that the downward trends in partnership rates may have been at least temporary broken.

\section{The Empirical Framework}

The aim is to model the partnership status of women, and in particular how the propensity to have a partner is affected by the benefit consequences of having a partner. Partnership status is treated as an individual choice. The elements of the model are as follows. Consider a set of females $I$ and let $s_{i}$ denote the partnership status of female $i \in I, s_{i}=0$ if she is single and $s_{i}=1$ if she has a partner. Each female $i \in I$ has some individual characteristics denoted by the vector $\mathbf{x}_{i} \in X$. The vector $\mathbf{x}_{i}$ contains e.g. age, education, number of children, race, region etc. (see below).

Each female is also associated with a (potential) partner with male characteristics $\mathbf{z}_{i} \in Z$. The characteristics of the partner of interest are the ones that allow us to compute welfare benefits; this includes hours of work, earnings, age, number and ages of children. In the analysis below I will assume that all men work (at least 16 hours/week), are above the age of 25 and that all children always reside with the females. ${ }^{14}$ The remaining characteristic in $\mathbf{z}_{i}$ is then earnings (see below). With respect to partner identity I assume that there is a well-defined "marriage-market" equilibrium which features some degree of equilibrium sorting. Specifically, female and male characteristics are not independent: $(\mathbf{x}, \mathbf{z})$ have some joint distribution which I take as exogenously given.

I also allow for the possibility that a woman's labour supply, and hence earnings, depends on her partnership status. To formalize this, let each female $i \in I$ be associated with two (exogenously given) potential labour supplies $\mathbf{h}_{i} \equiv\left(h_{i}^{0}, h_{i}^{1}\right)$ where $h_{i}^{0}$ is the labour supply as single and $h_{i}^{1}$ is the labour supply when partnered. Similarly, let $\mathbf{y}_{i} \equiv\left(y_{i}^{0}, y_{i}^{1}\right)$ be the vector containing female $i$ 's earnings in the single and partnered state respectively.

Benefit entitlement depends on partnership status, labour supply, earnings, individual characteristics (e.g. number and ages of children), and the partner's characteristics. Consider female $i$. Let $B_{i}^{c}=B^{c}\left(h_{i}^{1}, y_{i}^{1}, \mathbf{x}_{i}, \mathbf{z}_{i}\right)$ be the total benefits that female $i \in I$ and her partner are entitled to as a couple; let $B_{i}^{f}=B^{f}\left(h_{i}^{0}, y_{i}^{0}, \mathbf{x}_{i}\right)$ be the benefits that the female is entitled to as single

\footnotetext{
${ }^{14}$ Hence, in the empirical model, men are assumed to (i) not live as lone parents and (ii) not bring any children into a relationship.
} 
and let $B^{m}\left(\mathbf{z}_{i}\right)$ be the benefits that her partner is entitled to as single. Given that all men work at least 16 hours per week and that all children reside with the women the men will not be entitled to any benefits as single, $B_{i}^{m}=B^{m}\left(z_{i}\right)=0$ for all $i \in I$ (except for Tax Credits under the WTC). I further assume that a female, when with her partner, enjoys the full value of the total benefits obtained by the couple $B_{i}^{c}$. The net welfare benefit partnership bonus for female $i$ can then be defined as

$$
B_{i} \equiv B^{c}\left(h_{i}^{1}, y_{i}^{1}, \mathbf{x}_{i}, \mathbf{z}_{i}\right)-B^{f}\left(h_{i}^{0}, y_{i}^{0}, \mathbf{x}_{i}\right)-B^{m}\left(\mathbf{z}_{i}\right)
$$

Define the utility to female $i$ of being in state $s_{i} \in\{0,1\}$ as

$$
u_{i}^{s}=\left\{\begin{array}{cl}
\alpha B_{i}^{f}+\boldsymbol{\beta}^{0} \mathbf{x}_{i} & \text { if } s_{i}=0 \\
\alpha B_{i}^{c}+\boldsymbol{\beta}^{1} \mathbf{x}_{i} & \text { if } s_{i}=1
\end{array} .\right.
$$

Female $i$ will choose the partnered state if and only if $u_{i}^{1} \geq u_{i}^{0}$. Taking the difference and adding an stochastic utility component the utility difference can be written as

$$
u_{i}^{1}-u_{i}^{0}=\alpha B_{i}+\boldsymbol{\beta} \mathbf{x}_{i}+\varepsilon_{i}
$$

where $\boldsymbol{\beta} \equiv \boldsymbol{\beta}^{1}-\boldsymbol{\beta}^{0}$ and where I used that $B_{i}^{m}=0 .{ }^{15}$ Assuming that the error term $\varepsilon_{i}$ is normally distributed the model can then be estimated as simple probit model (see Eissa and Hoynes, 2003).

\section{Imputing Partners and Labour Supplies}

In order to characterize the partnership bonus $B_{i}$ for female $i$ we need to know, in addition to the woman's own characteristics $\mathbf{x}_{i}$, her (potential) partner's characteristics $\mathbf{z}_{i}$ and her potential labour supplies and earnings, $\mathbf{h}_{i}$ and $\mathbf{y}_{i}$. Two complications then immediately arise: (i) $\mathbf{z}_{i}$ is only observed for those women who actually have partners, and similarly, (ii) for each woman only one of her two potential labour supplies is observed, not both (and the same goes for earnings). Hence the unobserved values need to be imputed, i.e. we need to predict partners for the single women and we need to predict, for all women, labour supplies and earnings in the counterfactual partnership state.

\footnotetext{
${ }^{15}$ Under WTC $B_{i}^{m}$ can be positive. I therefore check for the sensitivity of using $B_{i} \equiv B_{i}^{c}-\left(B_{i}^{f}+B_{i}^{m}\right)$ as the measure of the partnership incentives by re-estimating the model using only $B_{i}^{c}-B_{i}^{f}$ as the benefit incentives for woman $i$ for having a partner. The alternative choice of specification has a negligible impact on the results.
} 
The justification for assuming that each female is associated with two potential labour supplies, one of which needs to be imputed, is two-fold: (i) to avoid bias, and, relatedly, (ii) to ensure that identification of the model comes from variation across groups and time, not from within groups of similar women at a given point in time. The obvious alternative would be to assume that the labour supply of each individual is fixed across partnership states. Consider then a certain group of women - low-educated mothers with one child, say - in any given year. We know that, within this group, the single mothers work considerably less frequently than their partnered comparables. Under the assumption of fixed labour supplies, the single mothers would then, on average, be facing higher IS partnership penalties (since they would, as single, be entitled to IS more frequently). Hence if we were to use the assumption of fixed labour supplies, we would find an "IS effect" - IS partnership penalties would be found to discourage partnership formation within the group of low-educated mothers of one child in the specific year. ${ }^{16}$ However, such an estimate would be strongly driven by the assumption of fixed labour supplies. A plausible assumption is that single and partnered women with the same characteristics are "intrinsically identical": had the currently single women had partners, they would have worked as frequently as their partnered comparables. Conversely, had the currently partnered women been single they would have had the same work patterns as their single comparables. Similarly, had the currently single women had partners, their partners would have been no different from the partners of their partnered comparables. In that case we should find no effects of benefits within groups of women that share the same characteristics and year. In short, since within any group and year, the single- and partnered women have the same work-patterns across partnership states and have identical (potential) partners, they will have identical distributions of partnership bonuses and penalties, thus implying zero correlation between partnership status and partnership bonuses/penalties within that group/year. Stated differently, it is assumed that partnership status is purely random within groups of women that share the same characteristics and are observed at the same time.

In order to formalize the above assumptions and to impute labour supplies and partners I adopt a simple "matching approach". For woman $i \in I$ let $\mathcal{I}^{1}(i)$ be the partnered women in the sample who are "similar" to $i$; similarly, again for woman $i \in I$ let $\mathcal{I}^{0}(i)$ be the single women

\footnotetext{
${ }^{16} \mathrm{On}$ the other hand we would most likely find, within the same group/year, a negative effect of tax credit partnership bonuses on the probability of having a partner since the single women would, under the assumption of fixed, labor supplies, have on average higher tax credit partnership bonuses.
} 
in the sample who are "similar" to $i$. (Below I describe what is the criterion for being deemed as "similar".) When imputing the counterfactual labour supply of a given woman $i$ I thus use as controls the set of similar women observed in the opposite partnership state. Similarly when imputing partner characteristics for woman $i$ I use as controls the set of similar women who are currently partnered women. In fact, I predict partners for all women. One justification for this is that current earnings may reflect significant temporary shocks; the predicted earnings can then be thought of as a measure of the (predicted) partner's permanent income. ${ }^{17}$

It remains to specify how we judge women to be "similar". I use the standard Mahalanobis metric with a maximum distance criterion; the "distance" between female $i$ and $j$ is thus defined as $d_{i j} \equiv\left[\left(\mathbf{x}_{i}-\mathbf{x}_{j}\right)^{\prime} \mathbf{V}\left(\mathbf{x}_{i}-\mathbf{x}_{j}\right)\right]^{1 / 2}$ where $\mathbf{V}$ is the sample covariance matrix (Lee, 2005). A number of covariates are, however, discrete. For these variables I insist on exact matching. Moreover, I only match within years. Hence female $j$ is deemed to be similar to female $i$ if she is observed in the same year, has the same value of the discrete characteristics, and the distance (for the continuous variables) $d_{i j}$ is no greater than some $d^{\max }$ (set equal to 2 ). The variables on which I match include age, age left full time education, number of dependent children, a parent dummy, living in a metropolitan area, and a set of regional dummies. ${ }^{18}$ The distribution of matches is described in detail in Table $1 .^{19}$

\section{Predicting Partners}

The male characteristic $z_{i}$ that needs to be predicted is earnings. I impute as partner earnings for woman $i \in I$ the average of the earnings of the partners in the $\operatorname{set} \mathcal{I}^{1}(i)$. The assumption on which the approach rests is that the partnership status is "purely random" for similar women. Specifically, I assume:

\section{Assumption 1. Conditional on the female characteristics $\mathbf{x}$, partnership status $s$ is independent}

\footnotetext{
${ }^{17}$ Note that the FRS data is a repeated cross-section, not a panel. Hence it is not possible to estimate permanent incomes using e.g. averaging across years.

${ }^{18}$ Region refers to "Government Office Region" and include North East, North West and Merseyside, Yorkshire and Humber, East Midlands, West Midlands, Eastern, London, South East, South West, Wales, Scotland and Northern Ireland.

${ }^{19}$ For single women we only need partnered controls (to impute counterfactual labour supply in the partnered state and partners). For partnered women we need single controls to impact counterfactual labour supply and partnered controls to impute partners. Thus, e.g. for partnered women we find on average 77 "similar" single women.
} 
of the partner's characteristic $z$.

The assumption implies that the distribution of earnings among the (would-be) partners of any woman with characteristics $\mathbf{x}$ is the same as the distribution of earnings among the actual partners of partnered women with characteristics $\mathbf{x} .{ }^{20}$ Hence I impute, for all $i \in I$, partner earnings by computing

$$
\widehat{z}_{i} \equiv \frac{\sum_{j \in \mathcal{I}^{1}(i)} z_{j}}{\# \mathcal{I}^{1}(i)} .
$$

The assumption effectively has two parts. First, it assumes that the observable female characteristics $\mathbf{x}$ determine a woman's "marriage market position" in the sense that they determine the what pool of men they will draw their potential partners from. Second, it assumes that the decision to form a partnership is depends on something else than the male characteristic, the obvious candidate being random feelings of "love".

\section{Predicting State-Specific Labour Supplies}

For each woman we observe only one of her two potential labour supplies: if she is single then we observe $h_{i}^{0}$ while if she has a partner we observe $h_{i}^{1}$. For simplicity I assume that women respond to partnerships by adjusting labour supplies only on the extensive margin - i.e. I will focus exclusively on the participation decision. Moreover, due to the key significance of the 16 hours/week cut-off in both IS and Tax Credit programme I define "participation" as working at least 16 hours/week. This restriction in focus is motivated by two observations: (i) for some types of women $\mathbf{x}$, the participation rate varies substantially with partnership status, but (ii) conditional on any set of characteristics $\mathbf{x}$ and conditional on participating, the hours worked vary relatively little with partnership status.

Figure 4 illustrates the first statement by showing how the participation rates differ for single and partnered women within various subgroups of sample. It shows how the partnershipeffect on participation is, for some subgroups and years, very large. Moreover the partnershipeffect varies intricately with educational attainment and parental status. Note also that, in the groups where substantial gaps exist, these gaps have diminished over time. The gap in hours (conditional on participation) is, on the other hand, relatively small; I find no group for whom

\footnotetext{
${ }^{20}$ By Assumption 1, there is, for each value of the female characteristics $\mathbf{x}$, a distribution of partner earnings $z$ from which observed earnings are random draws. We thus assign as predicted partner earnings for female $i$ the expected value $E\left[z \mid \mathbf{x}=\mathbf{x}_{i}\right]$ which we estimate using matching.
} 
the hours gap exceeds 10 percent. $^{21}$

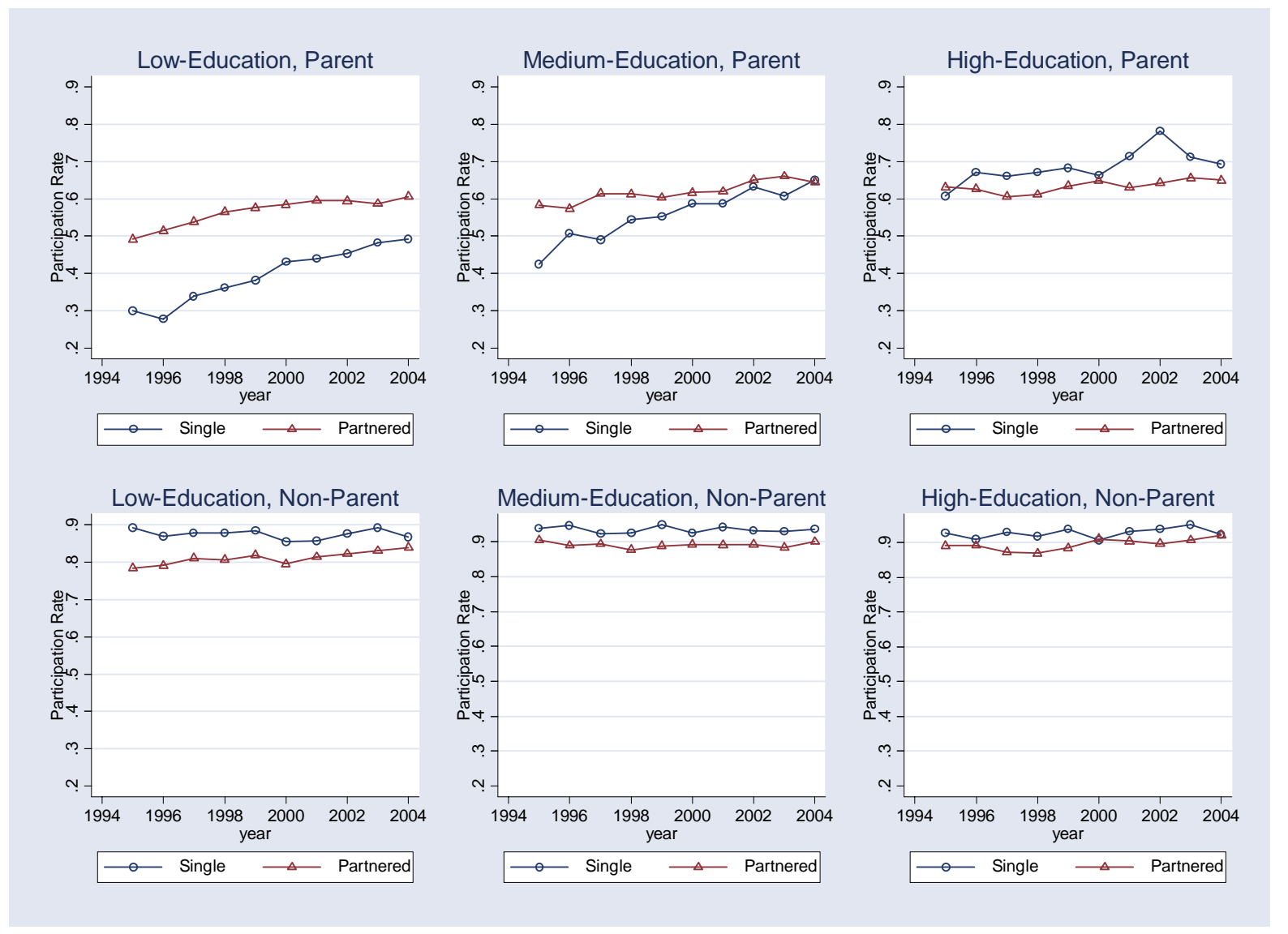

Figure 4: Participation rates (16hrs+) by partnership status among subgroups of women in the sample.

Given the focus on the extensive margin let $h_{i}^{0}$ and $h_{i}^{1}$ be dummy variables indicating female $i$ 's participation status in the single and partnered state respectively. The participation status in the actual state, denoted $h_{i}^{i}$, is observed while the participation decision in the counterfactual state, denoted $h_{i}^{-i}$, is not. Hence I need to predict $h_{i}^{-i}$ for all $i \in I$.

The approach I use again rests on the assumption that partnership status be "purely random" for women that share the same characteristics. Specifically, I assume:

\footnotetext{
${ }^{21}$ Defining the hours gap (conditional on participation) as the average hours worked by single participating women minus the average hours worked by partnered participating women, and pooling across years we have that the gap is $3.1 \mathrm{hrs}$ ( 8.8 percent) for low-educated non-parents, $1 \mathrm{hr}$ (2.7 percent) for medium-educated non-parents, -0.2 hrs (0.5 percent) for high-educated non-parents, -2 hrs (6.6 percent) for low-educated parents, 0.8 hrs (2.6 percent) for low-educated parents, 2 hrs (5.8 percent) for low-educated parents.
} 
Assumption 2. Conditional on the female characteristics $\mathbf{x}$, partnership status $s$ is independent of $\left(h^{0}, h^{1}\right)$.

This assumption implies that the would-be (partnered) participation rate of the currently single women with characteristics $\mathbf{x}$ is the same as the actual participation rate of the currently partnered women with the same characteristics (and vice versa).

The algorithm I use for imputing labour supplies in the counterfactual state ensures that Assumption 2 holds on a set of basic characteristics $\mathbf{x}$ while respecting the observed labour supplies to the largest extent possible. First I estimate individual participation probabilities in the counterfactual state using matching, estimating $\operatorname{Pr}\left(h_{i}^{-i}=1\right)$ by $\sum_{j \in \mathcal{I}^{-i}(i)} h_{j}^{-i} / \# \mathcal{I}^{-i}(i)$. Second, I split the population by education (low, medium, and high), number of dependent children $(0,1,2+)$, and year and compute group-specific participation rates by partnership status (a total of 180 means). Third, I assume that the participation decision of all women sharing these same basic characteristics respond to partnership status in the same direction. E.g. Figure 4 shows that single low educated non-parents work more frequently than their partnered counterparts. Hence I assume that any partnered women in this group who is observed to be working would continue to do so if she had been single; conversely, any single women observed not to be working is assumed to also be not working as partnered. This assumption pins down a counterfactual labour supply for the vast majority of women. Fourth, I draw, using the estimated participation probabilities from the first stage, a set of women whose participation decisions are predicted to vary with partnership status. I continue to draw women until Assumption 2 holds for all groups and years.

The distribution of actual- and predicted participation decisions is shown in Table 3. The table shows that more than 90 percent of all single women are predicted not to vary their labour force participation with partnership status. Slightly more than 6 percent of currently single women who are observed not to be working are predicted to join the labour force as partnered. Slightly less than 3 percent of the currently single women who are observed to be working are predicted to leave the labour force if they became single. The results for the partnered women are similar.

\section{Identification}

Assumption 1 and 2 used in the imputations are crucial to the identification strategy. The assumptions state that, among a group of women sharing the same characteristics, single women 
and partnered women are intrinsically identical in terms of their (state-specific) labour supplies and partners, and hence will have the same the distribution of partnership bonuses and penalties. In order to verify this, consider the nine basic "types" of women (also used extensively below) differing in (i) educational attainment (low-, medium-, and high), and (ii) number of children $(0,1,2+)$. For each year and each basic demographic type consider then the correlation between partnership status and net partnership bonus. With nine types, ten years and two policies (IS and Tax Credits) I thus compute 180 correlations and find no correlation to be statistically significant. Since I will also include type-dummies and year-dummies in the analysis below it follows that the effect of policy is identified from variation across groups and across time rather from cross-sectional variation within groups. This also emphasizes the importance of having policy reforms occurring within the time-frame of the analysis. As highlighted above, these policy reforms affected women of different types in quite different ways, thus allowing policy effects to be identified.

\section{Further Issues}

The current framework models the partnership status of women (single v. partnered) using repeated cross-sectional data. That framework has a number of potential shortcomings. First, as noted by Eissa and Hoynes (2003), it means that the model takes a "stock-approach" by looking at states. An alternative would have been to adopt a "flow-approach" by using panel data and looking at transitions. In order for the stock-approach to be valid it has to be assumed that all individuals effectively optimize on a period-by-period basis. It is also implicitly assumed that there are negligible search frictions in the "marriage market".

A related issue is the treatment of children. Children are treated in the current model as being effectively exogenous. However, children may of course be endogenous to the partnership status. E.g. a common modelling approach in dynamic modelling of family structure is to assume that there is an exogenous probability of child-bearing that varies by partnership state (see e.g. van der Klaauw (1996) and Brien, Lillard and Stern (2006)). Given the stock approach, the endogeneity of children is a concern since children are also correlated with benefit entitlement. Hence if children were left out of the set of regressors there would be a potential omitted variables bias.

A more complete model would thus take a dynamic approach with forward-looking individuals, incorporating potential search frictions and endogenizing fertility. However, such models 
tend to be very complex and few panel data sets are rich enough for such models to be estimated with any reasonable power. Hence in this case I choose to favour a simple stock approach in order to exploit the "large numbers" advantage of the repeated cross-sectional data.

\section{Results}

\section{Main Results}

Consider first the effect of the total (IS + Tax Credits) partnership bonus on the probability of having a partner. Table 4 (Column 1) presents the results from regressing partnership status, $s_{i} \in\{0,1\}$, on the partnership bonus $B_{i}$ (rescaled here as $£ 100$ per week), a set of demographic variables, year dummies and regional dummies. In order to allow for unrestricted interactions between education and number of children, I generate "type" dummies for the above nine basic demographic groups by interacting educational group (low-, medium-, and high) with number of children $(0,1,2+)$. High educated mothers of $2+$ children are left out as reference group. Moreover, in order to allow partnership trends to vary across these demographic groups, I interact the nine type dummies with time to generate nine "type-specific" additional linear trends.

The results suggest that high-educated mothers of two+ children are the most likely to have partners: all included type-dummies are negative and all are highly statistically significant. The effect of education on the probability of having a partner varies with parental status: among non-parents, there is no additional significant effect of education. On the other hand, for mothers with one child, education is positively associated with having a partner. The same holds for mothers with two or more children. There is also some evidence of type-specific trends.

Women living in metropolitan areas are less likely to have partners. The probability of having a partner increases in age (at a diminishing rate) over nearly the entire age range considered; moreover, the interaction between education and age is negative but small. In interpreting the coefficient on the number of children, it should be kept in mind that there are already dummies for having 0 or 1 child. Hence the coefficient is identified only from mothers of at least two children; among this group more children are actually negatively associated with having a partner. Mothers with young children are, on the other hand, more likely to have partners than mothers with only older children. Blacks are, in the data, much less likely to have partners than whites while Asians are slightly more likely to have partners. 
The results also suggest that women are more likely to have partners when there is benefit bonus from doing so. The coefficient on the total benefit partnership bonus suggests that a total partnership bonus of $£ 100$ /week increases the probability of having a partner by about 7 percentage points.

Recalling from Figure 2 that the overall average net (Tax Credit + IS) partnership bonus in the population has been a fairly constant weekly penalty of just over $£ 20$ per week, the result would suggest that the welfare benefits have been reducing the aggregate partnership rate by around one and a half percentage point. Below I also present calculations of the likely effect of the Tax Credit reforms.

Does it matter which benefit generates the partnership bonus/penalty? There are reasons to believe that it shouldn't. The two benefits share are least one important feature: they are both time unlimited. ${ }^{22}$ Hence it is interesting to see whether IS and Tax Credits generate similar responses. In Column 2 of Table 4 I present the results when IS and Tax Credits are included separately. The results suggest that it doesn't matter whether a partnership bonus/penalty is generated by the IS programme or by the Tax Credits - the coefficients are very similar. (As we will see, this only holds for this full specification.)

Table 5 reports on alternative specifications in order to examine the sensitivity of the basic result to the choice of control variables. Specification 1 controls only for a parent dummy. Adding controls for education (Low, Medium, or High) in Specification 2 has little effect on the estimate. Specification 3 adds year dummies to account for basic trends in the data. Specification 4 allows replaces the parent and education-type dummies with a finer partition of the basic demographic characteristics: it partitions the respondents into nine basic "types" by splitting them according to whether they have 0,1 or $2+$ children and interacting this with the educational group (see Table 4); the same specification also allows for additional "type-specific" linear trends. The main difference comes in Specification 5 which controls for additional demographics, mainly age and the presence of young children. Age and the presence of young children increases the probability of having a partner; both variables are also correlated with labour supply and hence with benefit entitlement. Omitting them therefore leads to a bias. Finally, Specification 6 reiterates the main specification from Table 4.

\footnotetext{
${ }^{22}$ The only way to be "timed out" of either programme (at least during the years considered here) was due to the children growing up. On the other hand, it should be pointed out that IS passports the recipient to a range of other benefits, including Housing Benefit and Council Tax Benefit.
} 


\section{Benefit Responses in Subgroups of the Population}

It is quite possible that the benefit responses differ among subgroups of the population. E.g. partnership rates were observed to vary across educational groups. Indeed, the ranking of the groups also varied over the lifecycle; e.g. low educated women were the most likely to have partners at low ages but the least likely to have partners in their late 30s and early 40s. Given that partnership patterns differ across educational groups we might suspect that the responsiveness to benefit partnership bonuses and penalties might vary across educational groups. Relatedly, since the value of benefits relative to expected earnings, both own and partner's, will be smaller for individuals with more education we would expect to see the benefit response to decrease with education.

It is also natural to conjecture that women with children will be less responsive to the incentives created by the welfare system. This could be because children raises the marginal value of having access to the earnings of a partner or because having a male figure present in the household is perceived to be beneficial for the child's development.

In order to explore these hypotheses I re-run the main regression within subgroups of the population. The results are presented in Table 6 . The table suggests that the responsiveness of partnership status to the financial incentives created by the benefit system indeed decreases with education, at least at higher levels. ${ }^{23}$ Parents and non-parents can best be compared on the IS effect since non-parents were not affected by tax credits under FC and WFTC. For IS, parents indeed respond less than non-parents. Tax credits only apply for non-parents under WTC, but here the model does not pick up any tax credit effect.

\section{The Tax Credit Reforms}

In this section I consider in some more detail the potential effect of the recent Tax Credit reforms on partnership rates. The family tax credits have, as shown above, in general an ambiguous effect on partnership incentives.

In order to explore the potential effects of the Tax Credit reforms it is important to get a handle on how exactly they affected the distribution of partnership penalties and bonuses. Figure 2 presented above provided some insights by showing how the distributions of Tax Credit

\footnotetext{
${ }^{23}$ This finding is in line with Eissa and Hoynes (2003) who find that the marriage responsiveness to transfers is lower among higher educated women.
} 
partnership bonuses and penalties have changed over time within the population. However, that figure has three shortcomings for the current purposes. First, it contains only existing couples, not single women. Second, the figure confounds the effect of time-variation in policy with trends in the distribution of demographic characteristics. Third, it assumes fixed labour supplies, in particular it doesn't allow women's labour supplies to vary with partnership status.

Hence we want to consider how the distribution of partnership bonuses and penalties has varied due to policy changes while (i) looking at the entire population, including the single women, (ii) holding the distribution of demographic characteristics fixed, and (iii) allowing for partnership state-specific labour supplies. To do this I take the population observed in one specific year and expose them to the policies of all years while computing benefit partnership bonuses and penalties using the individually predicted partners and state-specific labour supplies. Since the main interest is the Tax Credit reform it is appropriate to use the last cohort observed before the start of the reforms. Hence I consider the 1998 cohort and expose this particular cohort to the policies that were in place in each year from 1995 to 2004. The result is shown in Figure 5, stratified by education. For low educated women, Tax Credit partnership bonuses are more common than penalties; for medium educated women bonuses and penalties are equally common, while for high educated women partnership penalties are still more common than bonuses.

Consider first the 1999 WFTC reform. Figure 5 shows that that reform seems to have slightly increased the fraction of low educated women who face tax credit partnership bonuses. The reform is, however, more noticeable in the average bonuses and penalties. ${ }^{24}$ The figure shows how the average tax credit partnership bonus increased sharply in all education groups. At the same time the average partnership penalty also decreased slightly in all groups. The WFTC reform hence seems to have been unambiguously favourable to partnership formation. Indeed, looking at the aggregate population we see that the overall net Tax Credit partnership bonus turned from being a small net penalty of just a few pounds per week under FC to a fairly sizeable net partnership bonus of about $£ 10$ per week in $2001-2002 .^{25}$

\footnotetext{
${ }^{24}$ Note that we assume that everyone is observed in each year in the same month that they were observed in the 1998 survey. Hence for 1999 some individuals face the new WFTC system while some individuals face the old FC system; the full effect of the reform is visible from 2000 onwards.

${ }^{25}$ The reader may wonder why the fraction of couples subsidized increased gradually between 1999 and 2001 and not just as a single one off increase. The reason is two-fold. First, I assume that everyone is observed in each year in the same month that they were observed in the 1998 survey. Hence for 1999 some individuals face
} 
The impact of the WTC/CTC reform, which extended credits to childless individual and couples and consolidated the child premia provided under WFTC and IS into the unified CTC programme, was very different. That reform sharply increased the fraction of women facing Tax Credit partnership penalties: this increase was largely due to the Tax Credits becoming available to childless individuals and couples. It also sharply reduced the both the average tax credit bonus and the average tax credit penalty. The effect on the Tax Credits bonuses and penalties of shifting of the child premia from IS to CTC should however be matched by a corresponding change in the IS bonuses and penalties. This is indeed the case: in order to show this, Figure 5 also includes the total (IS + Tax Credits) average net partnership bonus. This shows that the transferring of the child premia from IS to CTC in 2004 had little effect on the combined effect of IS and Tax Credits.

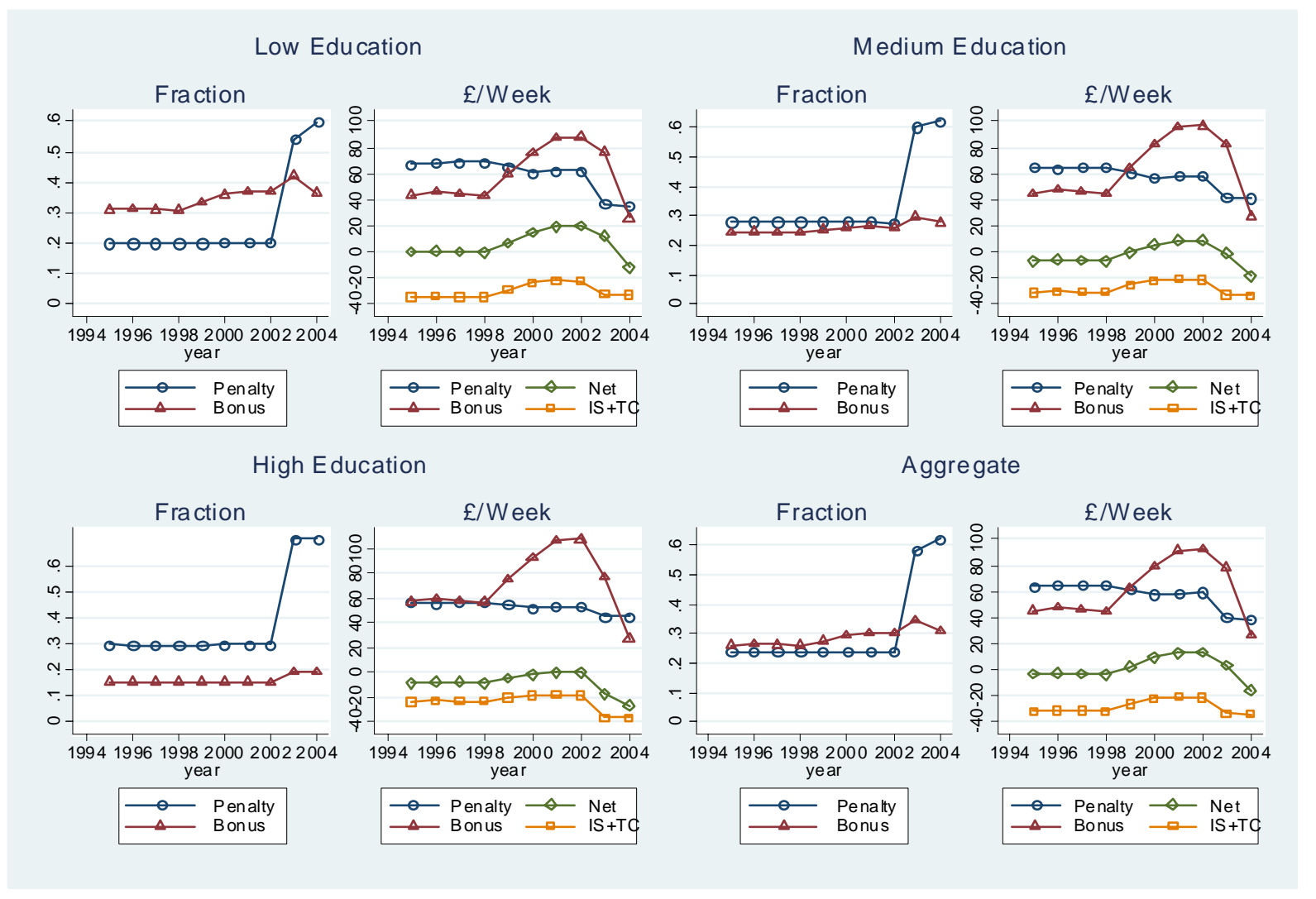

Figure 5: The distribution of Tax Credit partnership bonuses and penalties for a fixed population with state-specific labour supplies and predicted partners (2000 prices).

the new WFTC system while some individuals face the old FC system. Second, the Children's Tax Credit was introduced in 2001 (see Fn.9). 
Figure 5 thus highlights a curious pattern: while the WFTC reform seems to have been quite favourable to partnership formation, most, if not all, of its potential positive effect on partnership incentives also seems to have been undone by the subsequent WTC/CTC reform.

In order to obtain an indication of the potential impact of welfare policy on partnership rates, consider the WFTC reform. We can combine the impacts on the group-specific average net bonuses shown in Figure 5 with the group-specific estimated response rates presented in Table 6. For low educated women the WFTC reform increased the average net Tax Credit bonus by about $£ 15$ per week. This would imply an increased partnership rate in this group of little over one percentage point. The corresponding figure for the medium educated women would be around half a percentage point, while the response among high educated women would be negligible. Hence, the model suggests that if the WFTC programme had been allowed to continue it could potentially have increased the aggregate partnership rate by anything up to as much as 0.7 percentage points. Of course, the WFTC version of the Tax Credits was abandoned in favour of WTC/CTC which reversed the temporary improvement of partnership incentives.

The results on the potential programme effects are comparable to Eissa and Hoynes (2003). They explore the effect of the EITC on marriage. They conclude that the EITC system increases marriage rates among the lowest income households by about 1 percentage point while the effect is smaller as one moves up the income distribution.

\section{Conclusions}

The welfare system is commonly thought to affect important dimensions of individuals behavior, including when and how much to work, how much education to acquire, how much to save and maybe even if and when to form partnerships and have children. However, little concrete evidence on the effect of benefit systems on family structure is available for the UK. In this paper I have considered the incentives generated by the system of Income Support (IS) and the family Tax Credits (FC, WFTC, WTC/CTC) for partnership formation.

The empirical strategy used involved constructing, for each woman, the IS and Tax Credit partnership "bonus" or "penalty" that she is likely to be facing and then estimating a model where women's partnership status depends on individual characteristics, year- and regional

effect, and the constructed measure of the benefit consequences of having a partner. This empirical approach was motivated by the fact that Tax Credits in particular have an ambiguous effect on partnership incentives. Hence a standard difference-in-difference approach analyzing 
a particular reform may well fail to find any significant average treatment effect even if there are significant responses that tend to cancel out. The current paper nevertheless obtains, in difference-in-difference style, its identification from variation across groups and across time. In particular, the benefit response is identified from the fact that recent reforms have affected different groups in measurably different ways and the model effectively links this fact to the observed changes in the group-specific partnership rates.

The results indicate that a $£ 100 /$ week partnership penalty reduces the probability that a woman has a partner by about seven percentage points; moreover, the effect was the same if the benefit in question was IS or Tax Credits. I also found that the responsiveness to benefits decreases with education and that parents are less responsive than non-parents.

Finally I considered, in light of the estimates, what effect the recent Tax Credit reforms may have had on partnership rates. I found that the WFTC reform noticeably strengthened the benefit incentives for having a partner (or, perhaps more accurately, reduced the benefit disincentives for having a partner). Indeed, it was found that that version of the tax credits could potentially have increased the aggregate partnership rate by anything up to 0.7 percentage points. However, the subsequent WTC/CTC reform again deteriorated the partnership incentives and undid most, if not all, of the potential impact of the WFTC reform. 


\section{References}

Baughman, R. \& Dickert-Conlin, S. (2003), 'Did expanding the eitc promote motherhood?', American Economic Review Papers and Proceedings 93, 247-251.

Bitler, M. P., Gelbach, J. B., Hoynes, H. W. \& Zavodny, M. (2004), 'The impact of welfare reform on marriage and divorce', Demography 41, 213-36.

Blundell, R. (2002), 'Welfare-to-work: Which policies work and why?', British Academy Proceedings 117, 477-524. Keynes Lecture in Economics.

Blundell, R., Duncan, A., McCrae, J. \& Meghir, C. (2000), 'The labour market impact of the Working Families' Tax Credit', Fiscal Studies 21.

Blundell, R. \& Hoynes, H. (2004), Has in-work benefit reform helped the labour market?, in D. Card, R. Blundell \& R. Freeman, eds, 'Seeking a Premier League Economy', University of Chicago Press, chapter 10, pp. 411-460.

Brewer, M., Duncan, A., Shephard, A. \& Suarez, M. J. (2007), 'Did Working Families' Tax Credit work? Analysing the impact of in-work support on labour supply and programme participation', Labour Economics 13, 699-720.

Brewer, M. \& Shaw, J. (2006), 'How many lone parents are receiving tax credits?', Institute for Fiscal Studies, Briefing Note No. 70.

Brien, M. J., Lillard, L. A. \& Stern, S. N. (2006), 'Cohabitation, marriage and divorce in a model of match-quality', International Economic Review 47, 451-494.

Dickert-Conlin, S. \& Houser, S. (1999), 'EITC, AFDC, and the female headship decision'. Institute for Research on Poverty Discussion Paper no. 1192-99.

Eissa, N. \& Hoynes, H. (2000), 'Tax and transfer policy, and family formation: Marriage and cohabitation', Mimeo, University of California, Berkeley.

Eissa, N. \& Hoynes, H. W. (2003), 'Good news for low income families? Tax transfer schemes and marriage'. Mimeo, University of California, Berkeley.

Ellwood, D. T. (2000), 'The impact of the earned income tax credit and social policy reforms on work, marriage, and living arrangements', National Tax Journal 53, 1063-1106. 
Francesconi, M. \& van der Klaauw, W. (2007), 'The socioeconomic consequences of "in-work" benefit reform for British lone mothers', Journal of Human Resources 42, 1-31.

Gregg, P. \& Harkness, S. (2003), Welfare reform and lone parents employment in the UK, in R. Dickens, P. Gregg \& J. Wadsworth, eds, 'The Labour Market Under Labour: State of Working Britain 2003', Palgrave.

Hotz, V. J. \& Scholz, J. K. (2003), The earned income tax credit, in R. Moffitt, ed., 'MeansTested Transfer Programs in the U.S.', University of Chicago Press, Chicago, pp. 141-97.

Hoynes, H. W. (1997), 'Does welfare play any role in female headship decisions?', Journal of Public Economics 65, 89-117.

Lee, M.-J. (2005), Micro-Econometrics for Policy, Program, and Treatment Effects, Oxford University Press.

Moffitt, R. (1992), 'Incentive effects of the U.S. welfare system: A review', Journal of Economic Literature 30, 1-61.

Moffitt, R. (1998), The effect of welfare on marriage and the family, in R. Moffitt, ed., 'Welfare and Family and Reproductive Behavior', National Academy Press, Washington D.C.

Rosenzweig, M. (1999), 'Welfare, marital prospects, and nonmarital childbearing', Journal of Political Economy 107, S3-S22.

Schoeni, R. F. \& Blank., R. M. (2000), 'What has welfare reform accomplished? Impacts on welfare participation, employment, income, poverty, and family structure'. NBER Working Paper No. 7627.

Van der Klaauw, W. (1996), 'Female labour supply and marital status decisions: A life-cycle model', Review of Economic Studies 63, 199-235.

Walker, I. \& Zhu, Y. (2006), 'Child support and partnership dissolution', Economic Journal 106, C93-C116. 
Table 1: Descriptive statistics

\begin{tabular}{|c|c|c|}
\hline Variable & $\begin{array}{c}\text { Women with Partners } \\
\text { (Std. Err.) }\end{array}$ & $\begin{array}{c}\text { Women without Partners } \\
\text { (Std. Err.) }\end{array}$ \\
\hline Age & $\begin{array}{l}38.42 \\
(8.99)\end{array}$ & $\begin{array}{l}34.51 \\
(9.95)\end{array}$ \\
\hline Age left FT education & $\begin{array}{l}17.41 \\
(2.52)\end{array}$ & $\begin{array}{l}17.41 \\
(2.60)\end{array}$ \\
\hline Number dep. children & $\begin{array}{c}1.13 \\
(1.14)\end{array}$ & $\begin{array}{c}.79 \\
(1.08)\end{array}$ \\
\hline No. children aged $0-4$ & $\begin{array}{l}.33 \\
(.62)\end{array}$ & $\begin{array}{l}.20 \\
(.49)\end{array}$ \\
\hline No. children aged 5-10 & $\begin{array}{c}.39 \\
(.69)\end{array}$ & $\begin{array}{c}.30 \\
(.61)\end{array}$ \\
\hline No. children aged 11-15 & $\begin{array}{l}.30 \\
(.60)\end{array}$ & $\begin{array}{c}.23 \\
(.54)\end{array}$ \\
\hline No. children aged $16-18$ & $\begin{array}{l}.10 \\
(.33)\end{array}$ & $\begin{array}{c}.06 \\
(.26)\end{array}$ \\
\hline Weekly earnings & $\begin{array}{c}56.99 \\
(65.72)\end{array}$ & $\begin{array}{c}64.10 \\
(74.63)\end{array}$ \\
\hline Working $(16 \mathrm{hr}+)$ & $\begin{array}{l}.69 \\
(.46)\end{array}$ & $\begin{array}{l}.71 \\
(.45)\end{array}$ \\
\hline White & $\begin{array}{l}.94 \\
(.24)\end{array}$ & $\begin{array}{l}.92 \\
(.27)\end{array}$ \\
\hline Black & $\begin{array}{c}.01 \\
(.10)\end{array}$ & $\begin{array}{c}.04 \\
(.20)\end{array}$ \\
\hline Asian & $\begin{array}{c}.05 \\
(.22)\end{array}$ & $\begin{array}{c}.04 \\
(.20)\end{array}$ \\
\hline Metro & $\begin{array}{l}.48 \\
(.50)\end{array}$ & $\begin{array}{l}.53 \\
(.50)\end{array}$ \\
\hline Partner weekly earnings $\dagger$ & $\begin{array}{c}160.32 \\
(136.14)\end{array}$ & \\
\hline Predicted partner earnings & $\begin{array}{l}161.07 \\
(24.37)\end{array}$ & $\begin{array}{l}158.67 \\
(26.46)\end{array}$ \\
\hline
\end{tabular}


... table 1 continued

\begin{tabular}{|c|c|c|c|}
\hline Variable & \multicolumn{2}{|c|}{$\begin{array}{c}\text { Women with Partners } \\
\text { (Std. Err.) }\end{array}$} & $\begin{array}{l}\text { mithout } \\
\text { (Std. Err. }\end{array}$ \\
\hline Observations & \multicolumn{2}{|l|}{81,554} & 35,461 \\
\hline \multicolumn{4}{|l|}{$\dagger$ Average for employed partners. } \\
\hline \multicolumn{4}{|c|}{$\begin{array}{l}\text { Table 2: Distribution of matches for partnered and single } \\
\text { women. }\end{array}$} \\
\hline Target Group & Partnered & Partnered & Single \\
\hline Control Group & Single & Partnered & Partnered \\
\hline 10th Percentile & 21 & 52 & 49 \\
\hline Median & 71 & 154 & 157 \\
\hline Mean & 77.3 & 163.8 & 176.1 \\
\hline 90th Percentile & 147 & 287 & 326 \\
\hline
\end{tabular}


Table 3: Distribution of actual and predicted labour supplies.

\begin{tabular}{lcc}
\hline \hline & Single & \\
Case & Number & Frequency \\
\hline$h_{i}^{0}=1$ and $\widehat{h}_{i}^{1}=1$ & 24,158 & 68.13 \\
$h_{i}^{0}=0$ and $\widehat{h}_{i}^{1}=0$ & 8,020 & 22.62 \\
$h_{i}^{0}=0$ and $\widehat{h}_{i}^{1}=1$ & 2,263 & 6.38 \\
$h_{i}^{0}=1$ and $\widehat{h}_{i}^{1}=0$ & 1,020 & 2.88 \\
\hline \hline
\end{tabular}

Partnered

\begin{tabular}{lcc} 
Case & Number & Frequency \\
\hline$h_{i}^{1}=1$ and $\widehat{h}_{i}^{0}=1$ & 50,754 & 62.23 \\
$h_{i}^{1}=0$ and $\widehat{h}_{i}^{0}=0$ & 22,695 & 27.83 \\
$h_{i}^{1}=0$ and $\widehat{h}_{i}^{0}=1$ & 2,189 & 2.68 \\
$h_{i}^{1}=1$ and $\widehat{h}_{i}^{0}=0$ & 5,916 & 7.25 \\
\hline \hline
\end{tabular}


Table 4: Estimates of a probit model of partnership status

\begin{tabular}{|c|c|c|}
\hline Variable & $\begin{array}{c}\text { Marg. Eff. } \\
\text { (Std. Err.) }\end{array}$ & $\begin{array}{c}\text { Marg. Eff. } \\
\text { (Std. Err.) }\end{array}$ \\
\hline Partnership Bonus: Total Benefits & $\begin{array}{c}0.077 \\
(0.007)^{* *}\end{array}$ & \\
\hline Partnership Bonus: Income Support & & $\begin{array}{c}0.076 \\
(0.010)^{* *}\end{array}$ \\
\hline Partnership Bonus: Tax Credits & & $\begin{array}{c}0.076 \\
(0.007)^{* *}\end{array}$ \\
\hline Low-education, zero child & $\begin{array}{l}-0.419 \\
(0.024)^{* *}\end{array}$ & $\begin{array}{l}-0.419 \\
(0.024)^{* *}\end{array}$ \\
\hline Medium-education, zero child & $\begin{array}{l}-0.447 \\
(0.023)^{* *}\end{array}$ & $\begin{array}{l}-0.447 \\
(0.023)^{* *}\end{array}$ \\
\hline High-education, zero child & $\begin{array}{c}-0.466 \\
(0.023)^{* *}\end{array}$ & $\begin{array}{c}-0.466 \\
(0.023)^{* *}\end{array}$ \\
\hline Low-education, one child & $\begin{array}{l}-0.335 \\
(0.024)^{* *}\end{array}$ & $\begin{array}{l}-0.335 \\
(0.024)^{* *}\end{array}$ \\
\hline Medium-education, one child & $\begin{array}{c}-0.259 \\
(0.027)^{* *}\end{array}$ & $\begin{array}{l}-0.259 \\
(0.027)^{* *}\end{array}$ \\
\hline High-education, one child & $\begin{array}{l}-0.173 \\
(0.032)^{* *}\end{array}$ & $\begin{array}{l}-0.173 \\
(0.032)^{* *}\end{array}$ \\
\hline Low-education, two + child & $\begin{array}{c}-0.222 \\
(0.023)^{* *}\end{array}$ & $\begin{array}{l}-0.222 \\
(0.023)^{* *}\end{array}$ \\
\hline Medium-education, two + child & $\begin{array}{l}-0.087 \\
(0.024)^{* *}\end{array}$ & $\begin{array}{l}-0.087 \\
(0.024)^{* *}\end{array}$ \\
\hline Trend: Low-ed, zero child & $\begin{array}{l}-0.003 \\
(0.001)^{* *}\end{array}$ & $\begin{array}{l}-0.003 \\
(0.001)^{* *}\end{array}$ \\
\hline Trend: Medium-ed, zero child & $\begin{array}{l}-0.001 \\
(0.001)\end{array}$ & $\begin{array}{l}-0.001 \\
(0.001)\end{array}$ \\
\hline Trend: High-ed, zero child & $\begin{array}{c}0.004 \\
(0.002)^{* *}\end{array}$ & $\begin{array}{c}0.004 \\
(0.002)^{* *}\end{array}$ \\
\hline Trend: Low-ed, one child & $\begin{array}{l}-0.010 \\
(0.001)^{* *}\end{array}$ & $\begin{array}{l}-0.010 \\
(0.001)^{* *}\end{array}$ \\
\hline
\end{tabular}


... table 4 continued

\begin{tabular}{|c|c|c|}
\hline Variable & $\begin{array}{c}\text { Marg. Eff. } \\
\text { (Std. Err.) }\end{array}$ & $\begin{array}{c}\text { Marg. Eff. } \\
\text { (Std. Err.) }\end{array}$ \\
\hline Trend: Medium-ed, one child & $\begin{array}{c}-0.006 \\
(0.002)^{* *}\end{array}$ & $\begin{array}{c}-0.006 \\
(0.002)^{* *}\end{array}$ \\
\hline Trend: High-ed, one child & $\begin{array}{l}-0.001 \\
(0.003)\end{array}$ & $\begin{array}{l}-0.001 \\
(0.003)\end{array}$ \\
\hline Trend: Low-ed, two+ child & $\begin{array}{c}-0.008 \\
(0.001)^{* *}\end{array}$ & $\begin{array}{c}-0.008 \\
(0.001)^{* *}\end{array}$ \\
\hline Trend: Medium-ed, two+ child & $\begin{array}{c}-0.006 \\
(0.002)^{* *}\end{array}$ & $\begin{array}{c}-0.006 \\
(0.002)^{* *}\end{array}$ \\
\hline Trend: High-ed, two+ child & $\begin{array}{c}-0.001 \\
(0.003)\end{array}$ & $\begin{array}{c}-0.001 \\
(0.003)\end{array}$ \\
\hline Living in metropolitan area & $\begin{array}{c}-0.028 \\
(0.004)^{* *}\end{array}$ & $\begin{array}{c}-0.028 \\
(0.004)^{* *}\end{array}$ \\
\hline Age & $\begin{array}{c}0.049 \\
(0.001)^{* *}\end{array}$ & $\begin{array}{c}0.049 \\
(0.001)^{* *}\end{array}$ \\
\hline Age squared & $\begin{array}{c}-0.0005 \\
(0.0000)^{* *}\end{array}$ & $\begin{array}{c}-0.0005 \\
(0.0000)^{* *}\end{array}$ \\
\hline Age $*$ Age left FT educ. & $\begin{array}{c}-0.0001 \\
(0.0000)^{* *}\end{array}$ & $\begin{array}{c}-0.0001 \\
(0.0000)^{* *}\end{array}$ \\
\hline Number of dep. children & $\begin{array}{c}-0.043 \\
(0.003)^{* *}\end{array}$ & $\begin{array}{c}-0.043 \\
(0.004)^{* *}\end{array}$ \\
\hline Young child (0-4) present & $\begin{array}{c}0.141 \\
(0.004)^{* *}\end{array}$ & $\begin{array}{c}0.141 \\
(0.004)^{* *}\end{array}$ \\
\hline Black & $\begin{array}{c}-0.307 \\
(0.011)^{* *}\end{array}$ & $\begin{array}{c}-0.307 \\
(0.011)^{* *}\end{array}$ \\
\hline Asian & $\begin{array}{c}0.060 \\
(0.006)^{* *}\end{array}$ & $\begin{array}{c}0.060 \\
(0.006)^{* *}\end{array}$ \\
\hline Observations & 117,015 & 117,015 \\
\hline
\end{tabular}

Significance levels: $\quad *: 5 \% \quad * *: 1 \%$

Remark: Explanatory variables not shown are year dummies and regional dummies. 
Table 5: Estimates of a probit model of partnership status:

Alternative specifications

\begin{tabular}{lcc}
\hline \multicolumn{1}{c}{ Specification } & $\begin{array}{c}\text { Net IS Bonus } \\
(\text { Std. Err. })\end{array}$ & $\begin{array}{c}\text { Net Tax Credit Bonus } \\
\text { (Std. Err.) }\end{array}$ \\
\hline Specification 1: & 0.043 & 0.032 \\
Parent dummy & $(0.008)^{* *}$ & $(0.006)^{* *}$ \\
Specification 2: & 0.035 & 0.029 \\
Parent dummy, Ed grp (low, medium, high) & $(0.008)^{* *}$ & $(0.006)^{* *}$ \\
Specification 3: & 0.053 & 0.041 \\
As 2 plus year dummies & $(0.008)^{* *}$ & $(0.006)^{* *}$ \\
Specification 4: & 0.045 & 0.037 \\
Type dummies and Type-spec. trends & $(0.009)^{* *}$ & $(0.007)^{* *}$ \\
Specification 5: & 0.090 & 0.083 \\
As Spec 5 plus more demographics & $(0.009)^{* *}$ & $(0.007)^{* *}$ \\
Specification 6: & 0.076 & 0.076 \\
As Spec 6 plus region and metro & $(0.010)^{* *}$ & $(0.007)^{* *}$ \\
\hline
\end{tabular}

Significance levels: $\quad *: 5 \% \quad * *: 1 \%$ 
Table 6: Estimates of a probit model of partnership status:

Subgroups of the population.

\begin{tabular}{lccc}
\hline \hline \multicolumn{1}{c}{ Subgroup } & $\begin{array}{c}\text { IS Bonus } \\
\text { (Std. Err.) }\end{array}$ & $\begin{array}{c}\text { Tax Credit Bonus } \\
\text { (Std. Err. })\end{array}$ & Observations \\
\hline Low Educations & 0.074 & 0.097 & 61,815 \\
& $(0.012)^{* *}$ & $(0.009)^{* *}$ & \\
Medium Education & 0.092 & 0.075 & 33,553 \\
& $(0.021)^{* *}$ & $(0.015)^{* *}$ & \\
High Education & 0.052 & 0.018 & 21,647 \\
& $(0.025)^{*}$ & $(0.018)$ & \\
Parents & 0.043 & 0.057 & 64,771 \\
& $(0.012)^{* *}$ & $(0.008)^{* *}$ & \\
Non-Parents & 0.109 & -0.006 & 52,244 \\
& $(0.015)^{* *}$ & 0.031 & \\
\hline
\end{tabular}

Significance levels: $\quad *: 5 \% \quad * *: 1 \%$ 


\section{CESifo Working Paper Series}

for full list see www.cesifo-group.org/wp

(address: Poschingerstr. 5, 81679 Munich, Germany, office@cesifo.de)

2084 Robert Fenge, Maximilian von Ehrlich and Matthias Wrede, Fiscal Competition, Convergence and Agglomeration, August 2007

2085 Volker Nitsch, Die Another Day: Duration in German Import Trade, August 2007

2086 Kam Ki Tang and Jie Zhang, Morbidity, Mortality, Health Expenditures and Annuitization, August 2007

2087 Hans-Werner Sinn, Public Policies against Global Warming, August 2007

2088 Arti Grover, International Outsourcing and the Supply Side Productivity Determinants, September 2007

2089 M. Alejandra Cattaneo and Stefan C. Wolter, Are the Elderly a Threat to Educational Expenditures?, September 2007

2090 Ted Bergstrom, Rod Garratt and Damien Sheehan-Connor, One Chance in a Million: Altruism and the Bone Marrow Registry, September 2007

2091 Geraldo Cerqueiro, Hans Degryse and Steven Ongena, Rules versus Discretion in Loan Rate Setting, September 2007

2092 Henrik Jacobsen Kleven, Claus Thustrup Kreiner and Emmanuel Saez, The Optimal Income Taxation of Couples as a Multi-Dimensional Screening Problem, September 2007

2093 Michael Rauber and Heinrich W. Ursprung, Life Cycle and Cohort Productivity in Economic Research: The Case of Germany, September 2007

2094 David B. Audretsch, Oliver Falck and Stephan Heblich, It's All in Marshall: The Impact of External Economies on Regional Dynamics, September 2007

2095 Michael Binder and Christian J. Offermanns, International Investment Positions and Exchange Rate Dynamics: A Dynamic Panel Analysis, September 2007

2096 Louis N. Christofides and Amy Chen Peng, Real Wage Chronologies, September 2007

2097 Martin Kolmar and Andreas Wagener, Tax Competition with Formula Apportionment: The Interaction between Tax Base and Sharing Mechanism, September 2007

2098 Daniela Treutlein, What actually Happens to EU Directives in the Member States? - A Cross-Country Cross-Sector View on National Transposition Instruments, September 2007 
2099 Emmanuel C. Mamatzakis, An Analysis of the Impact of Public Infrastructure on Productivity Performance of Mexican Industry, September 2007

2100 Gunther Schnabl and Andreas Hoffmann, Monetary Policy, Vagabonding Liquidity and Bursting Bubbles in New and Emerging Markets - An Overinvestment View, September 2007

2101 Panu Poutvaara, The Expansion of Higher Education and Time-Consistent Taxation, September 2007

2102 Marko Koethenbuerger and Ben Lockwood, Does Tax Competition Really Promote Growth?, September 2007

2103 M. Hashem Pesaran and Elisa Tosetti, Large Panels with Common Factors and Spatial Correlations, September 2007

2104 Laszlo Goerke and Marco Runkel, Tax Evasion and Competition, September 2007

2105 Scott Alan Carson, Slave Prices, Geography and Insolation in $19^{\text {th }}$ Century AfricanAmerican Stature, September 2007

2106 Wolfram F. Richter, Efficient Tax Policy Ranks Education Higher than Saving, October 2007

2107 Jarko Fidrmuc and Roman Horváth, Volatility of Exchange Rates in Selected New EU Members: Evidence from Daily Data, October 2007

2108 Torben M. Andersen and Michael Svarer, Flexicurity - Labour Market Performance in Denmark, October 2007

2109 Jonathan P. Thomas and Tim Worrall, Limited Commitment Models of the Labor Market, October 2007

2110 Carlos Pestana Barros, Guglielmo Maria Caporale and Luis A. Gil-Alana, Identification of Segments of European Banks with a Latent Class Frontier Model, October 2007

2111 Felicitas Nowak-Lehmann D., Sebastian Vollmer and Immaculada Martínez-Zarzoso, Competitiveness - A Comparison of China and Mexico, October 2007

2112 Mark Mink, Jan P.A.M. Jacobs and Jakob de Haan, Measuring Synchronicity and Comovement of Business Cycles with an Application to the Euro Area, October 2007

2113 Ossip Hühnerbein and Tobias Seidel, Intra-regional Tax Competition and Economic Geography, October 2007

2114 Christian Keuschnigg, Exports, Foreign Direct Investment and the Costs of Corporate Taxation, October 2007

2115 Werner Bönte, Oliver Falck and Stephan Heblich, Demography and Innovative Entrepreneurship, October 2007 
2116 Katrin Assenmacher-Wesche and M. Hashem Pesaran, Assessing Forecast Uncertainties in a VECX Model for Switzerland: An Exercise in Forecast Combination across Models and Observation Windows, October 2007

2117 Ben Lockwood, Voting, Lobbying, and the Decentralization Theorem, October 2007

2118 Andrea Ichino, Guido Schwerdt, Rudolf Winter-Ebmer and Josef Zweimüller, Too Old to Work, too Young to Retire?, October 2007

2119 Wolfgang Eggert, Tim Krieger and Volker Meier, Education, Unemployment and Migration, October 2007

2120 Stefan Napel and Mika Widgrén, The European Commission - Appointment, Preferences, and Institutional Relations, October 2007

2121 Bertil Holmlund and Martin Söderström, Estimating Income Responses to Tax Changes: A Dynamic Panel Data Approach, October 2007

2122 Doina Maria Radulescu, From Separate Accounting to Formula Apportionment: Analysis in a Dynamic Framework, October 2007

2123 Jelle Brouwer, Richard Paap and Jean-Marie Viaene, The Trade and FDI Effects of EMU Enlargement, October 2007

2124 Kurt R. Brekke, Luigi Siciliani and Odd Rune Straume, Competition and Waiting Times in Hospital Markets, October 2007

2125 Alexis Direr, Flexible Life Annuities, October 2007

2126 Johannes Becker and Clemens Fuest, Quality versus Quantity - The Composition Effect of Corporate Taxation on Foreign Direct Investment, October 2007

2127 Balázs Égert, Real Convergence, Price Level Convergence and Inflation Differentials in Europe, October 2007

2128 Marko Koethenbuerger, Revisiting the "Decentralization Theorem" - On the Role of Externalities, October 2007

2129 Axel Dreher, Silvia Marchesi and James Raymond Vreeland, The Politics of IMF Forecasts, October 2007

2130 Andreas Knabe and Ronnie Schöb, Subsidizing Extra Jobs: Promoting Employment by Taming the Unions, October 2007

2131 Michel Beine and Bertrand Candelon, Liberalization and Stock Market Co-Movement between Emerging Economies, October 2007

2132 Dieter M. Urban, FDI Technology Spillovers and Wages, October 2007 
2133 Valentina Bosetti, Carlo Carraro, Emanuele Massetti and Massimo Tavoni, Optimal Energy Investment and R\&D Strategies to Stabilise Greenhouse Gas Atmospheric Concentrations, October 2007

2134 David-Jan Jansen and Jakob de Haan, The Importance of Being Vigilant: Has ECB Communication Influenced Euro Area Inflation Expectations?, October 2007

2135 Oliver Falck, Heavyweights - The Impact of Large Businesses on Productivity Growth, October 2007

2136 Xavier Freixas and Bruno M. Parigi, Banking Regulation and Prompt Corrective Action, November 2007

2137 Jan K. Brueckner, Partial Fiscal Decentralization, November 2007

2138 Silvia Console Battilana, Uncovered Power: External Agenda Setting, Sophisticated Voting, and Transnational Lobbying, November 2007

2139 Alan J. Auerbach, Michael P. Devereux and Helen Simpson, Taxing Corporate Income, November 2007

2140 Lorenzo Cappellari, Paolo Ghinetti and Gilberto Turati, On Time and Money Donations, November 2007

2141 Roel Beetsma and Heikki Oksanen, Pension Systems, Ageing and the Stability and Growth Pact, November 2007

2142 Hikaru Ogawa and David E. Wildasin, Think Locally, Act Locally: Spillovers, Spillbacks, and Efficient Decentralized Policymaking, November 2007

2143 Alessandro Cigno, A Theoretical Analysis of the Effects of Legislation on Marriage, Fertility, Domestic Division of Labour, and the Education of Children, November 2007

2144 Kai A. Konrad, Mobile Tax Base as a Global Common, November 2007

2145 Ola Kvaløy and Trond E. Olsen, The Rise of Individual Performance Pay, November 2007

2146 Guglielmo Maria Caporale, Yannis Georgellis, Nicholas Tsitsianis and Ya Ping Yin, Income and Happiness across Europe: Do Reference Values Matter?, November 2007

2147 Dan Anderberg, Tax Credits, Income Support and Partnership Decisions, November 2007 